\title{
Predicting the Risk of Developing New Cerebral Lesions After Stereotactic Radiosurgery or Fractionated Stereotactic Radiotherapy for Brain Metastases from Renal Cell Carcinoma
}

\author{
DIRK RADES ${ }^{1}$, LIESA DZIGGEL $^{1}$, OLIVER BLANCK ${ }^{2}$, \\ NIKLAS GEBAUER ${ }^{3}$, TOBIAS BARTSCHT ${ }^{3}$ and STEVEN E. SCHILD ${ }^{4}$ \\ Departments of ${ }^{1}$ Radiation Oncology and ${ }^{2}$ Hematology and Medical Oncology, \\ University of Lübeck, Lübeck, Germany; \\ ${ }^{3}$ Saphir Radiosurgery Center Northern Germany, Güstrow, Germany; \\ ${ }^{4}$ Department of Radiation Oncology, Mayo Clinic, Scottsdale, AZ, U.S.A.
}

\begin{abstract}
Aim: To create an instrument for estimating the risk of new brain metastases after stereotactic radiosurgery (SRS) or fractionated stereotactic radiotherapy (FSRT) alone in patients with renal cell carcinoma (RCC). Patients and Methods: In 45 patients with 1-3 brain metastases, seven characteristics were analyzed for association with freedom from new brain metastases (age, gender, performance score, number and sites of brain metastases, extra-cerebral metastasis, interval from RCC diagnosis to SRS/FSRT). Results: Lower risk of subsequent brain lesions after RT was associated with single metastasis $(p=0.043)$ and supratentorial involvement only $(p=0.018)$. Scoring points were: One metastasis=1,2-3 metastases $=0$, supratentorial alone $=1$, infratentorial with/without supratentorial $=0$. Scores of 0,1 and 2 points were associated with 6-month rates of freedom from subsequent brain lesions of 25\%, 74\% and $92 \%(p=0.008)$. After combining groups with 1 and 2 points, 6-month rates were $25 \%$ for those with 0 points and $83 \%$ for those with 1-2 points $(p=0.002)$. Conclusion: Two groups were identified with different risks of new brain metastases after SRS or FSRT alone. High-risk patients may benefit from additional whole-brain irradiation.
\end{abstract}

In about $10 \%$ of all patients with renal cell carcinoma (RCC), brain metastases occur during the course of their disease $(1$

Correspondence to: Professor Dirk Rades, MD, Department of Radiation Oncology, University of Lübeck, Lübeck, Ratzeburger Allee 160, 23562 Lübeck, Germany. Tel: +49 45150045401, Fax: +4945150045404, e-mail: rades.dirk@gmx.net

Key Words: Brain metastases, stereotactic radiosurgery, fractionated stereotactic radiotherapy, renal cell carcinoma, freedom from new brain metastases, scoring instrument.
2). Most patients with four or more cerebral lesions receive whole-brain irradiation (WBI) alone or WBI supplemented by a boost. In patients with oligo-metastatic disease (most often defined as 1-3 lesions) focal therapies such as neurosurgical resection, stereotactic radiosurgery (SRS) and fractionated stereotactic radiotherapy (FSRT), either alone or in combination with WBI, are more popular (1-4). Since the indication for neurosurgical resection is generally limited to single accessible lesions, SRS and FSRT are more frequently used than neurosurgery for patients with very few brain metastases from RCC (5). One important question is whether the treatment results of SRS/FSRT can be improved with the addition of WBI. Since two randomized trial demonstrated that the addition of WBI leads to an increase in neurocognitive deficits $(6,7)$, many radiation oncologists are quite reluctant to add WBI to SRS/FSRT, particularly in patients with very few brain metastases from a less radiosensitive malignancy such as RCC. However, both randomized trials and two other prospective trials have shown that addition of WBI results in better intracerebral control, particularly regarding freedom from new cerebral lesions (6-9). An intracerebral recurrence can also have a negative impact on neurocognitive function (10). Therefore, it would be helpful prior to commencing treatment to identify patients who are at a high risk of developing new brain metastases and who could potentially benefit from the addition of WBI. This study aimed to create an instrument specifically for patients with RCC to help physicians estimate the risk of an individual patient developing new brain metastases after SRS or FSRT alone.

\section{Patients and Methods}

The data of 45 consecutive patients who received SRS alone for 13 brain metastases from RCC at each contributing center were retrospectively evaluated with respect to the risk of developing new 
Table I. Distributions of the seven characteristics investigated in patients with renal cell carcinoma treated with stereotactic radiosurgery (SRS) or fractionated stereotactic radiotherapy (FSRT).

\begin{tabular}{lc}
\hline Characteristic & Number of patients $(\%)$ \\
\hline Age at time of SRS/FSRT & \\
$\leq 64$ Years & $22(49)$ \\
$\quad \geq 65$ Years & $23(51)$ \\
Gender & \\
$\quad$ Female & $9(20)$ \\
Male & $36(80)$ \\
Karnofsky Performance Score & \\
$60-70$ & $16(36)$ \\
$80-100$ & $29(64)$ \\
Number of cerebral metastases & \\
1 & $21(47)$ \\
$2-3$ & $24(53)$ \\
Site of cerebral metastasis & \\
Supratentorial alone & $26(58)$ \\
Infra-/supratentorial & $9(20)$ \\
Unknown or unclear & $10(22)$ \\
Extra-cerebral metastasis & \\
No & $16(36)$ \\
Yes & $29(64)$ \\
Interval between diagnosis and SRS/FSRT & \\
$\leq 18$ Months & $22(49)$ \\
$\geq 19$ Months & $23(51)$ \\
\hline
\end{tabular}

cerebral lesions outside the irradiated areas of the brain. The doses of SRS (median=20 Gy, range=16-25 Gy) and FSRT (3-5 fractions of 6-10 Gy) were prescribed to the outer margin of the metastases, representing isodose levels between $75 \%$ and $90 \%$. Seven characteristics were analyzed regarding their potential impact on freedom from new brain metastases. These characteristics were: age at the time of SRS ( $\leq 64 v s . \geq 65$ years; median $=65$ years), gender, Karnofsky performance score (KPS) (60-70 vs. 80-100), number of brain metastases (1 vs. 2-3), sites of the treated brain metastases (supratentorial vs. infratentorial with/without supratentorial), presence of extrarcerebral metastases (no $v s$. yes) and the interval between diagnosis of RCC and delivery of SRS ( $\leq 18 v s . \geq 19$ months; median=19 months). The distributions of the seven characteristics are summarized in Table I.

Freedom from new brain metastases was estimated with the Kaplan-Meier method using JMP v.13 (SAS Co. Cary, N.C., USA). The Wilcoxon test was used to identify significant differences between Kaplan-Meier curves (11). $p$-Values of less than 0.05 on Wilcoxon test were considered significant. The characteristics found to be significantly associated with freedom from new brain metastases were included in the scoring instrument.

\section{Results}

The 6- and 12-month rates of freedom from new brain metastases for all seven characteristics are shown in Table II. A lower risk of developing new cerebral lesions outside the irradiated areas was significantly associated with the presence of a single metastasis $(p=0.043)$ and supratentorial
Table II. Univariate analysis of freedom from new cerebral metatsases in patients with renal cell carcinoma treated with stereotactic radiosurgery (SRS) or fractionated stereotactic radiotherapy (FSRT).

\begin{tabular}{|c|c|c|c|}
\hline \multirow[b]{2}{*}{ Characteristic } & \multicolumn{2}{|c|}{$\begin{array}{l}\text { Freedom from new } \\
\text { brain metastases }\end{array}$} & \multirow[b]{2}{*}{$p$-Value } \\
\hline & $\begin{array}{c}\text { At } 6 \\
\text { months }(\%)\end{array}$ & $\begin{array}{c}\text { At } 12 \\
\text { months }(\%)\end{array}$ & \\
\hline \multicolumn{4}{|c|}{ Age at time of SRS/FSRT } \\
\hline$\leq 64$ Years & 77 & 44 & \\
\hline$\geq 65$ Years & 74 & 68 & 0.741 \\
\hline \multicolumn{4}{|l|}{ Gender } \\
\hline Female & 76 & 76 & \\
\hline Male & 76 & 51 & 0.931 \\
\hline \multicolumn{4}{|c|}{ Karnofsky Performance Score } \\
\hline $60-70$ & 79 & 63 & \\
\hline $80-100$ & 77 & 56 & 0.485 \\
\hline \multicolumn{4}{|c|}{ Number of cerebral metastases } \\
\hline 1 & 89 & 77 & \\
\hline $2-3$ & 62 & 23 & 0.043 \\
\hline \multicolumn{4}{|c|}{ Site of cerebral metastasis } \\
\hline Supratentorial alone & 85 & 68 & \\
\hline Infra-/supratentorial & 44 & 44 & 0.018 \\
\hline \multicolumn{4}{|c|}{ Extra-cerebral metastasis } \\
\hline No & 81 & 59 & \\
\hline Yes & 72 & 56 & 0.457 \\
\hline \multicolumn{4}{|c|}{$\begin{array}{l}\text { Interval between diagnosis } \\
\text { and SRS/FSRT }\end{array}$} \\
\hline$\leq 18$ Months & 75 & 56 & \\
\hline$\geq 19$ Months & 77 & 59 & 0.888 \\
\hline
\end{tabular}

Significant $p$-values are shown in bold.

involvement $(p=0.018)$. These two characteristics were included in the scoring instrument. Since the metastatic sites were unknown or not absolutely clear in 10 patients, scores were assigned to 35 patients. The following points were allocated: only one metastasis $=1$ point, $2-3$ metastases $=0$ points, supratentorial involvement alone $=1$ point, infratentorial with/without supratentorial involvement $=0$ points. Thus, the possible scores for individual patients were $0(n=4), 1(n=18)$ or $2(n=13)$ points. The corresponding 6month rates of freedom from new brain metastases were $25 \%, 74 \%$ and $92 \%$, respectively, with 12 -month rates of $25 \%, 62 \%$ and $75 \%$, respectively ( $p=0.008$, Figure 1$)$. Since the rates of the groups with 1 point and 2 points were relatively close, these two groups were combined. The 6- and 12-month rates of freedom from new brain metastases of groups scoring 0 points and $1-2$ points were $25 \%$ vs. $83 \%$ and $25 \% v s .69 \%$, respectively ( $p=0.002$, Figure 2 ).

\section{Discussion}

Due to research activities and the recent introduction of new anticancer drugs, the survival of patients with RCC is 


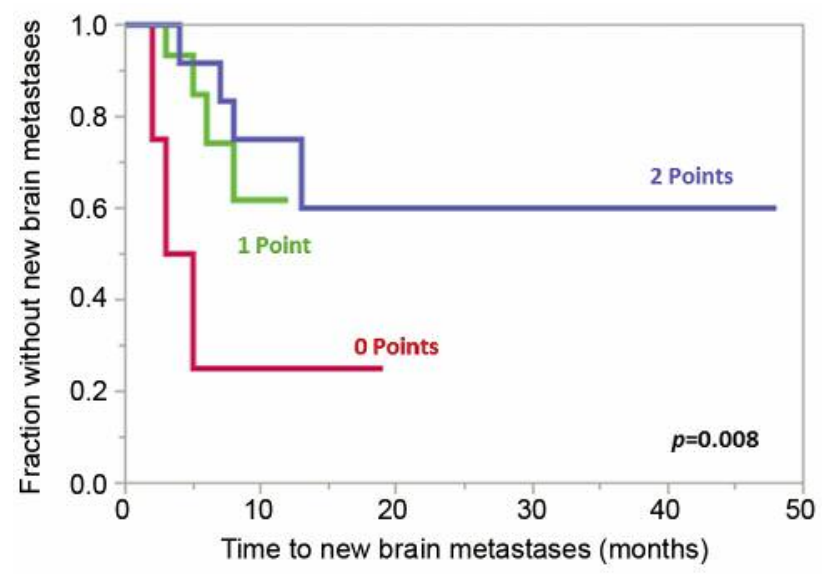

Figure 1. Analysis of freedom from new brain metatsases: KaplanMeier curves for groups with scores of 0,1 and 2. The p-value was obtained from the Wilcoxon test.

improving (12-15). Since the risk of developing brain metastases increases with lifespan, the number of patients with brain metastases from RCC also increases. When brain metastases are diagnosed, many patients have multiple lesions and receive WBI (1). However, a considerable number of patients present with only very few lesions. For the treatment of patients with 1-3 metastases, focal therapies play an important role (1). The majority of these patients receive SRS or FSRT alone or in combination with WBI.

The addition of WBI can have a negative effect on neurocognitive function including processing speed, delayed memory and recognition $(6,7)$. In a randomized trial of 58 patients from 2009, neurocognitive deficits were observed in $24 \%$ of patients at 4 months after SRS alone and in $96 \%$ of patients after SRS with WBI $(p<0.001)(6)$. In a more recent randomized trial of 213 patients, the rates of cognitive deterioration assessed at 3 months following irradiation were $63.5 \%$ after SRS alone and $91.7 \%$ after SRS with WBI, respectively $(p<0.001)$ (7). However, in both randomized trials, intra-cerebral control was significantly better after SRS with WBRT than after SRS alone. In the trial from 2009 , the 1-year intra-cerebral control rates were $73 \%$ and $27 \%$, respectively $(p<0.001)(6)$. In the trial from 2016 , intra-cerebral control rates at 3 months were $93.7 \%$ and $75.3 \%$, respectively $(p<0.001)$, and were also significantly better after SRS with WBI at 6 and 12 months following irradiation (7). These results were confirmed by two other randomized trials $(8,9)$. The authors of a subgroup analysis of one of the latter two trials suggested that intracerebral control is very important in preserving neurocognitive function (10). Taking into account the arguments for and against addition of WBI to SRS/FSRT, it becomes clear that it would be very helpful to be able to estimate a patient's risk

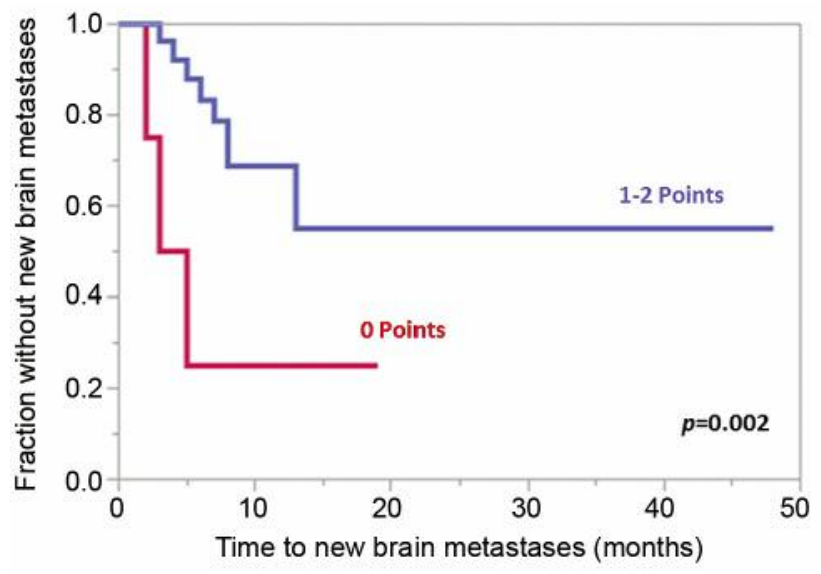

Figure 2. Analysis of freedom from new brain metatsases: KaplanMeier curves for two prognostic groups with scores of 0 points and 1-2 points. The p-value was obtained from the Wilcoxon test.

of developing new brain metastases outside the irradiated cerebral areas after SRS/FSRT alone in order to help prescribe the most appropriate treatment regimen.

The present study was conducted to create a scoring instrument to support physicians when they make treatment decisions. Such instruments are available for patients with brain metastases in general and specifically for patients with brain metastases from lung cancer, malignant melanoma and breast cancer (16-19). It is reasonable to develop specific instruments for single tumor entities, since malignant tumors have different biological behaviors and prognoses. RCC is considered unique because it has a comparably low radiosensitivity. In the present study, two prognostic groups were identified based on two significant predictors of freedom from new brain metastases, namely the number of cerebral lesions and site of metastasis. The number of brain metastases was also significantly associated with the development of new brain metastases in studies of patients with brain metastases from lung cancer and from melanoma (16-18). The impact of the metastatic site on the development of new brain metastases is unique. In other studies, performance score and presence of extra-cerebral metastases were identified as prognostic factors $(16,17,19)$. The fact that there are differences between various tumor types regarding the predictors of new brain metastases supports the concept that variations in behavior suggest the need for specific scoring instruments for each type.

Taking into account the results of the present study, the probability of freedom from new brain metastases after 6 months was only $25 \%$ in patients with a score of 0 points. These patients would be those most likely to benefit from the addition of WBI to SRS/FSRT. In contrast, the probability of freedom from new brain metastases was $83 \%$ after 6 months 
and still $69 \%$ after 12 months in patients with scores of 1 or 2 points. Therefore, these patients appear to be unlikely to benefit from the addition of WBI. However, when considering these suggestions, one should be aware of the retrospective nature of this study, which bears the risk of hidden selection biases.

In conclusion, two prognostic groups were identified with a significantly different risk of developing new brain metastases outside the irradiated areas of the brain after SRS or FSRT alone. Patients of the high-risk group may benefit from the addition of WBI to STS/FSRT.

\section{Conflicts of Interest}

On behalf of all Authors, the corresponding Author states that there is no conflict of interest related to this study.

\section{References}

1 Tsao MN, Rades D, Wirth A, Lo SS, Danielson BL, Gaspar LE, Sperduto PW, Vogelbaum MA, Radawski JD, Wang JZ, Gillin MT, Mohideen N, Hahn CA and Chang EL: Radiotherapeutic and surgical management for newly diagnosed brain metastasis(es): An American Society for Radiation Oncology evidence-based guideline. Pract Radiat Oncol 2: 210-225, 2012.

2 Siegel RL, Miller KD and Jemal A: Cancer statistics, 2017. CA Cancer J Clin 67: 7-30, 2017.

3 Rades D, Hornung D, Veninga T, Schild SE and Gliemroth J: Single brain metastasis: radiosurgery alone compared with radiosurgery plus up-front whole-brain radiotherapy. Cancer 118: 2980-2985, 2012.

4 Rades D, Veninga T, Hornung D, Wittkugel O, Schild SE and Gliemroth J: Single brain metastasis: whole-brain irradiation plus either radiosurgery or neurosurgical resection. Cancer 118 : 1138-1144, 2012.

5 Bindal RK, Sawaya R, Leavens ME and Lee JJ: Surgical treatment of multiple brain metastases. J Neurosurg 79: 210-216, 1993.

6 Chang EL, Wefel JS, Hess KR, Allen PK, Lang FF, Kornguth DG, Arbuckle RB, Swint JM, Shiu AS, Maor MH and Meyers CA: Neurocognition in patients with brain metastases treated with radiosurgery or radiosurgery plus whole-brain irradiation: a randomised controlled trial. Lancet Oncol 10: 1037-1044, 2009.

7 Brown PD, Jaeckle K, Ballman KV, Farace E, Cerhan JH, Anderson SK, Carrero XW, Barker FG 2nd, Deming R, Burri SH, Ménard C, Chung C, Stieber VW, Pollock BE, Galanis E, Buckner JC and Asher AL: Effect of radiosurgery alone vs. radiosurgery with whole brain radiation therapy on cognitive function in patients with 1 to 3 brain metastases: A Randomized Clinical Trial. JAMA 316: 401-409, 2016.

8 Aoyama H, Shirato H, Tago M, Nakadawa K, Toyoda T, Hatano K, Kenjyo M, Oya N, Horota S, Snioura H, Kunieda E, Inomata T, Hayakawa K, Katoh $\mathrm{N}$ and Kobashi G: Stereotactic radiosurgery plus whole-brain radiation therapy $v s$. stereotactic radiosurgery alone for treatment of brain metastases. A randomized controlled trial. JAMA 295: 2483-2491, 2006.
9 Kocher M, Soffietti R, Abacioglu U, Villà S, Fauchon F, Baumert BG, Fariselli L, Tzuk-Shina T, Kortmann RD, Carrie C, Ben Hassel M, Kouri M, Valeinis E, van den Berge D, Collette S, Collette L and Mueller RP: Adjuvant whole-brain radiotherapy versus observation after radiosurgery or surgical resection of one to three cerebral metastases: results of the EORTC 22952-26001 study. J Clin Oncol 29: 134-141, 2011.

10 Aoyama H, Tago M, Kato N, Toyoda T, Kenjyo M, Hirota S, Shioura H, Inomata T, Kunieda E, Hayakawa K, Nakagawa K, Kobashi $\mathrm{G}$ and Shirato $\mathrm{H}$ : Neurocognitive function of patients with brain metastasis who received either whole-brain radiotherapy plus stereotactic radiosurgery or radiosurgery alone. Int J Radiat Oncol Biol Phys 68: 1388-1395, 2007.

11 Kaplan EL and Meier P: Non parametric estimation from incomplete observations. J Am Stat Assoc 53: 457-481, 1958.

12 Kadono Y, Kawaguchi S, Nohara T, Shigehara K, Narimoto K, Izumi K, Ikeda H, Yaegashi H, Miyagi T, Nakashima T, Seto C and Mizokami A: Evaluation of factors affecting metastasis for renal cell carcinoma based on current guidelines in Japan. Anticancer Res 37: 5147-5153, 2017.

13 Korashy HM, Maayah ZH, Al Anazi FE, Alsaad AM, Alanazi IO, Belali OM, Al-Atawi FO and Alshamsan A: Sunitinib inhibits breast cancer cell proliferation by inducing apoptosis, cell-cycle arrest and DNA repair while inhibiting NF-kB signaling pathways. Anticancer Res 37: 4899-4909, 2017.

14 Zhao Q, Kun D, Hong B, Deng X, Guo S, Tang X, Yang Y, Gong K, Li Q, Ye L, Jiang WG, and Zhang N: Identification of novel proteins interacting with vascular endothelial growth inhibitor 174 in renal cell carcinoma. Anticancer Res 37: 43794388, 2017.

15 Yamaguchi N, Osaki M, Onuma K, Yumioka T, Iwamoto H, Sejima T, Kugoh H, Takenaka A and Okada F: Identification of microRNAs involved in resistance to sunitinib in renal cell carcinoma cells. Anticancer Res 37: 2985-2992, 2017.

16 Huttenlocher S, Dziggel L, Hornung D, Blanck O, Schild SE and Rades D: A new prognostic instrument to predict the probability of developing new cerebral metastases after radiosurgery alone. Radiat Oncol 9: 215, 2014.

17 Huttenlocher S, Sehmisch L, Schild SE, Blank O, Hornung D and Rades D: Identifying melanoma patients with 1-3 brain metastases who may benefit from whole-brain irradiation in addition to radiosurgery. Anticancer Res 34: 5589-5592, 2014.

18 Rades D, Huttenlocher S, Khoa MT, Thai PV, Hornung D and Schild SE: Number of cerebral lesions predicts freedom from new brain metastases after radiosurgery alone in lung cancer patients. Oncol Lett 10: 1109-1112, 2015.

19 Dziggel L, Dahlke M, Janssen S, Hornung D, Blanck O, Khoa MT, Schild SE and Rades D: Predicting the risk of new cerebral lesions after stereotactic radiosurgery (SRS) for brain metastases from breast cancer. Anticancer Res 35: 6793-6797, 2015.

Received March 8, 2018

Revised March 27, 2018

Accepted March 28, 2018 